\title{
Prediction of concrete creep and shrinkage: past, present and future ${ }^{\text {tr }}$
}

\author{
Zdeněk P. Bažant* \\ Walter P. Murphy Professor of Civil Engineering and Materials Science, Northwestern University, Evanston, IL 60208, USA
}

Received 17 September 1999; received in revised form 22 May 2000; accepted 24 May 2000

\begin{abstract}
The first part of the paper summarizes various aspects of the prediction of concrete creep and shrinkage to be discussed in the conference lecture. They include the theories of physical mechanism, prediction models, constitutive equations, computational approaches, probabilistic aspects, and research directions. The second part then presents two new prediction models. One of them deals with the approximate prediction formulae for pore relative humidity distributions, required for realistic creep and shrinkage analysis, and the other deals with the extrapolation of short time measurements of creep and shrinkage into long times. (C) 2001 Elsevier Science B.V. All rights reserved.
\end{abstract}

\section{Introduction}

A long time has elapsed since the first observations of concrete shrinkage in the previous century and the discovery of concrete creep in 1907 by Hatt (RILEM Recommendation, 1998). Much research has been devoted to this complex problem ever since. However, despite major successes, the phenomenon of creep and shrinkage is still far from being fully understood, even though is has

\footnotetext{
Paper presented at the Joint WANO/OECD-NEA Workshop: Prestress Loss in NPP Containments, Poitiers, France, 25-27 August, 1997.

* Tel.: + 1-847-4914125; fax: + 1-847-4671078.

E-mail address: z-bazant@northwestern.edu (Z.P. Bažant).
}

occupied some of the best minds in the field on cement and concrete research and materials science - Glanville, Dischinger, Troxell et al. (1958), Pickett, McHenry, L'Hermite et al. (1965), Arutyunian, Aleksandrovskii (1959), Powers, Hansen and Mattock (1966), Rüsch, Neville et al., (1983), Trost, Dilger, Wittman, Hilsdorf, Müller, Huet, Carol, to name but a few (RILEM TC-69, 1988a). The present lecture will attempt to review the highlights of the past successes, explain some basic physical mechanisms and mathematical concepts, appraise our current capabilities and suggest some profitable future research directions and applications. Due to time and space limitations, the review will be far from exhaustive. Also, it will be flavored by the orientation of previous studies at the writer's institution. 
The present brief paper $^{1}$ will give in the first part a brief summary of the main points, as seen by the writer. In the second part, one new and one recent mathematical developments will be presented in some detail.

\section{Review of basic results and issues}

Correct mathematical prediction of concrete creep and shrinkage inevitably requires understanding of the physical mechanism. It is generally accepted that drying shrinkage is caused by capillary tension, solid surface tension, and withdrawal of hindered adsorbed water and interlayer water from cement gel. Further shrinkage, called autogeneous, is also produced by chemical volume changes (which could be negative, i.e. expansive) and self-desiccation. As for creep, many mechanisms causing creep or influencing it have been proposed and studied:

1. Plastic flow.

2. Consolidation theory.

3. Load-bearing hindered adsorbed water.

4. Bond breakage in slip and its reformation.

5. Nonlinear deformations and cracking as a contribution to Pickett effect.

6. Solidification theory for short-term aging (Bažant and Prasannan, 1989).

7. Microprestress of creep sites in cement gel microstructure, causing the Pickett effect and long-term aging (Bažant et al., 1997).

As it turned out, the last two suffice to explain most if not all the basic experimental evidence.

The early mathematical models were formulated with a view to facilitate structural analysis. But computers made it possible to use any type of model, and thus the recent modeling could focus on representing the experimental data as closely as possible. The following prediction models (RILEM TC-69, 1988a) have been proposed, although those numbered 1-3 have been superseded by newer ones:

\footnotetext{
${ }^{1}$ This paper was written in 1997 solely for the purpose of a conference lecture, and therefore is not quite in the style of an archival journal article.
}

1. Dichinger-Glanville theory, or rate-of-creep model (or theory of aging).

2. Updated Dischinger model or rate-of-flow model.

3. Arutyunian-Maslov model.

4. Double power law and log-double power law for basic creep.

5. BP and BPKX models and, as the latest version, the B3 model.

The first three models attempt a certain simplification of structural analysis. In this regard, the simplest methods to use are:

- Effective modulus method (much simpler than Dischinger methods yet not involving a larger error).

- Age-adjusted effective modulus method (AAEM).

Formulation of a comprehensive prediction model is a very difficult task. In view of the limited knowledge we possess, the problem of model formulation does not have a unique answer. Probably different models can describe the current knowledge equally well. However, they cannot be very different because a model acceptable today must not only fit the existing data (Müller, RILEM data bank), but should also conform to the mathematical consequences of several well established physical phenomena, including:

1. Activation energy theory of bond ruptures (temperature dependence of aging and of creep viscosities).

2. Diffusion theory, particularly its simple asymptotic properties for initial and final drying or shrinkage.

3. Modeling of cracking due to residual stresses in the cross section as a mechanism of apparent shrinkage reduction.

4. Solidification theory, particularly the fact that aging is only an apparent feature and must be caused by solidification-deposition of unstressed layers of hydration products on the pore walls.

5. Microprestress, which causes additional apparent long-term aging that cannot be explained by volume growth of hydration products.

6. Effect of fracture growth on apparent creep (the nonlinear part of creep is probably noth- 
ing but the effect of time-dependent crack growth).

In detail, see RILEM TC-107 (1995) Guidelines.

Aside from aging, the most difficult aspect of creep is the humidity variation, particularly the drying creep effect, also called the Pickett effect. A number of mathematical models have been proposed to describe it:

1. Pickett's model with creep nonlinearity.

2. Microdiffusion of hindered adsorbed or interlayer water and changes of disjoining pressure (manifested as stress-induced shrinkage).

3. Shrinkage reduction due to tensile cracking (Wittmann in the 1970s; Bažant and Xi, 1974; Alvaredo and Wittmann, 1993) or by tensile strain softening (Bažant and $\mathrm{Wu}, 1974$ ).

4. Microprestress of highly localized creep sites in cement gel caused by humidity (and temperature) changes.

Combination of the last two appears to provide the proper predictive model.

Among prediction models one must distinguish:

- True constitutive equations, describing the behavior of a small representative volume of concrete, and

- Models for the approximate overall (mean) behavior of the cross section of a long member.

The latter models are inevitably much more complicated in their form, because they must also characterize the solution of the boundary value problem of evolution of humidity distributions, residual stresses and cracking. However, the former models are much more difficult to identify from test data because their fitting to data involves an inverse boundary layer problem.

With the availability of finite element programs, the practice should shift from models for cross section behavior to the direct use of constitutive equation. This of course means splitting the cross section into a number of finite elements. Only this approach can satisfy the hope for good predictions.

Computational approaches of various types (e.g. Bažant, 1994, 1995; RILEM Recommendation, 1998) have been developed:

1. One-step approximate solutions using the ageadjusted effective modulus method.
2. Step-by-step solution according to the integral-type creep model based on the principle of superposition.

3. Step-by-step solution according to a rate-type creep model based on the Kelvin or Maxwell chain.

The last approach gives the most realistic results, because only the rate-type model allows physically sound incorporation of the effects of varying pore humidity and temperature on creep and aging.

Considerable strides have been made in the probabilistic modeling, which is very important because of high statistical variability, and in micromechanics of the effect of concrete composition on creep and shrinkage (e.g. Granger and Bažant, 1995; Baweja et al., 1998). Nevertheless, the best way to achieve good long-time predictions is to conduct short-time tests on the given concrete and then extrapolate them (preferebly statistically, in a Bayesian manner) on the basis of a good prediction model incorporating as much as possible of the physics of creep.

For future research, the following avenues seem most promising and important:

1. Updating of long-term predictions on the basis of short-time measurements, with the use of probabilistic concepts.

2. Incorporating into structural analysis the solutions of pore humidity and temperature distributions in the cross section.

3. Mastering the interaction of creep with fracture (Bažant, 1993, 1995).

4. Micromechanical modeling and use of composite material theories for predicting creep and shrinkage from the properties of constituents.

5. Improved thermodynamical theory for the effects of pore water and temperature.

6. Nonlinear triaxial creep at high stress, especially taking into account time-dependent fracture and damage growth.

7. Improved, physically-based, probabilistic modeling of creep and shrinkage.

8. Creep and shrinkage of high strength and special concretes.

9. The means to reduce shrinkage and, for some applications, creep (the stress relaxation due to creep is sometimes beneficial). 


\section{Two new mathematical models}

\subsection{Study of explicit approximate formulae for predicting pore humidity distributions}

Realistic prediction of the effects of creep and shrinkage in concrete structures exposed to drying environment requires the calculation of the distributions of relative humidity in the pores of concrete at various times. Although it is not difficult to solve the problem numerically by finite difference or finite element solutions of the nonlinear diffusion equation for concrete drying (e.g. Bažant and Najjar, 1972; Xi et al., 1996; RILEM TC-69, 1988; Bažant and Raftshol, 1982; Bažant and Kim, 1991), simple explicit formulas are desired by structural analysts.

One very simple formula was presented by Parrott (1991). However a close examination shows that this formula may be oversimplified. It was compared only to a rather limited set of data, and does not agree well with the broader experimental evidence (for example that used in Bažant and Najjar, 1972; Xi et al., 1995). Besides, this formula does not conform to the asymptotic behavior for very short and very long times, which should be easy to satisfy by an explicit formula. Furthermore, since the water loss is approximately proportional to the drop in the average relative humidity in the pores, and the drying shrinkage is approximately proportional to the water loss, the average humidity obtained from the formula should evolve in time similarly as shrinkage, for which plentiful data are available and a rather accurate prediction model has been developed (Bažant and Baweja, 1995a,b,c, 2000).

At Northwestern University, in a study yet unpublished, Z.P. Bažant and M.T. Kazemi (Visiting Scholar on leave from Sharif University of Technology, Tehran) developed an improved simple formulation that exhibits correct asymptotic behaviors, agrees better with the measurements of pore relative humidity, and also agrees better with the shrinkage prediction formula. Although calibration by Kazemi is still in progress, a preliminary form of this formulation will be briefly outlined in this section.
We limit attention to a drying process that may be approximately considered as one-dimensional in space. The cross section may be that of a wall limited by two parallel planes. As an approximation, rectangular or square cross sections, as well as a cube and prism can be treated similarly, using cylindrical or spherical coordinates.

The average relative humidity in the pores is defined as:

$\bar{h}(t)=\frac{1}{D} \int_{0}^{D} h(x, t) \mathrm{d} x$

in which $t$, time and $D$, thickness of cross section. Because the change of average humidity is approximately proportional to the average shrinkage in the cross section, the shrinkage prediction formula in Bažant and Baweja (1995) indicates that:

$$
\begin{gathered}
\frac{\varepsilon_{\mathrm{sh}}(t)}{\varepsilon_{\mathrm{sh} \infty}\left(h_{\mathrm{e}}\right)}=\frac{w_{0}-\bar{w}(t)}{w_{0}-w_{\infty}\left(h_{\mathrm{e}}\right)}=\frac{h_{0}-\bar{h}(t)}{h_{0}-h_{\mathrm{e}}}-\tanh \xi, \\
\xi=\sqrt{\frac{t-t_{0}}{\tau_{\mathrm{sh}}}}
\end{gathered}
$$

in which $h_{0}$, initial relative humidity in the pores, assumed to be uniform (usually between 95 and $100 \%) ; h_{\mathrm{e}}$, environmental relative humidity; $\varepsilon_{\mathrm{sh}}$, average shrinkage strain in the cross section; $\varepsilon_{\mathrm{sh} \infty}$, final value of shrinkage strain corresponding to $h_{\mathrm{e}} ; w_{0}$, initial specific evaporable water content in concrete; $\bar{w}$, average specific water content; $w_{\infty}$, final water loss corresponding to $h_{\mathrm{e}}$; and $t_{0}$, initial time at the start of exposure to drying environment; $t-t_{0}=$ duration of drying; $\tau_{\mathrm{sh}}$, shrinkage or drying half-time, which is expressed as:

$\tau_{\mathrm{sh}}=k_{t}\left(k_{\mathrm{s}} D\right)^{2}$

Here $D$ is generally defined as the effective cross section thickness, $D=2 v / s$, where $v$ and $s$ are the volume and the surface of the structural member. $D$ must be given in inches, and $t, t_{0}$ in days. The parameter $k_{\mathrm{t}}$ can be predicted from the empirical expressions $k_{t}=190.8 t_{0}^{-0.08} \quad f_{c}^{\prime}{ }^{-1 / 4}$ days in. ${ }^{-2}$ in which $f_{c}^{\prime}$ is the average uniaxial compression strength which must be given in psi.

The tangent-hyperbolic function in Eq. (2) (Fig. 1 right) satisfies two basic asymptotic properties, which are exhibited by the solutions of the nonlinear diffusion equation (Bažant and Kim, 1991a,b): 
for $t-t_{0} \ll \tau_{\mathrm{sh}}$ :

$$
\tanh \xi=\xi-\frac{1}{3} \xi^{3}+\frac{2}{15} \xi^{5}-\cdots \approx \xi
$$

for $t-t_{0} \gg \tau_{\mathrm{sh}}$ :

$$
\begin{aligned}
\tanh \xi & =1-2\left(e^{-2 \xi}-e^{-4 \xi}+e^{-6 \xi}-\cdots\right) \\
& \approx 1-2 e^{-2 \xi}
\end{aligned}
$$

Thus, the function tanh $\psi$ is justified as a simple interpolation between these two opposite asymptotic behaviors. There are other functions that can match these asymptotic behaviors, but they are more complicated. The pore humidity distributions at various times can be approximately assumed as power curves, given by the expression:

for $x \leq \delta(t): h(x, t)$

$$
=h_{\mathrm{c}}(t)-\left[h_{\mathrm{c}}(t)-h_{\mathrm{e}}\right]\left(1-\frac{x}{\delta(t)}\right)^{\gamma} ;
$$

for $\delta(t) \leq x \leq D: h(x, t)=h[\delta(t), t]$

(see Fig. 1); $\gamma$, empirical constant. For linear diffusion theory, the profiles can be closely approximated as parabolas, in which case $\gamma=2$. Due to the nonlinearity of diffusion in concrete, consisting primarily in the fact that the diffusivity greatly decreases with the decrease of humidity (about 20 times as the humidity drops from 0.95 to 0.7 ), the optimum value of exponent $\gamma>2$. Usually the best

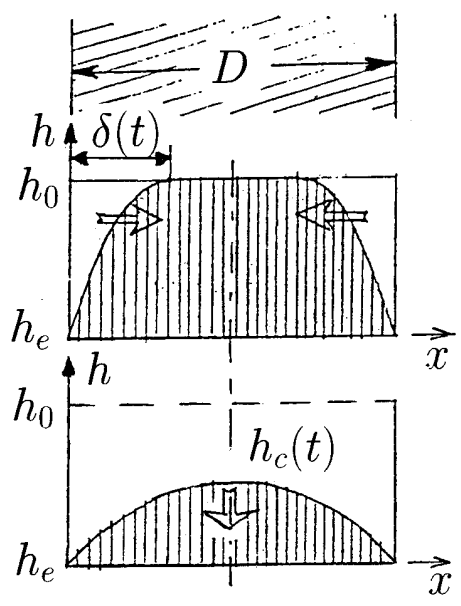

Fig. 1. Approximate parabolic profiles of pore humidity in the first and second stages of drying of a wall, and time evolution of average humidity or shrinkage. fit is obtained for $\gamma=3$ or 4 . Parameter $\delta$ represents the depth of penetration of the drying front. After the drying fronts from the opposite surfaces meet, $\delta=D / 2=$ constant and parameter $h_{\mathrm{c}}$ represents the pore humidity in the center of the thickness of the cross section. Before that, $h_{\mathrm{c}}$ represents also the humidity at the front of drying, i.e. $h_{\mathrm{c}}=h_{0}$.

As is well known from exact diffusion solutions, the drying process can be divided in two stages: during the first stage, the drying front advances, which continues until the drying fronts meet in the center of the cross section. During that stage, the humidity profiles are scaled horizontally, i.e. are being transformed by affinity in the horizontal direction with respect to a vertical axis on the surface (Fig. 1 left). During the second stage, the humidity profiles are being scaled down, transformed by affinity in the vertical direction with respect to a horizontal axis (see Fig. 1 middle).

To obtain an expression for parameters $\delta(t)$ and $h_{\mathrm{c}}(t)$, we may substitute (5) into the averaging integral 1, and match the result to the average humidity obtained from Eq. (2). After various algebraic rearrangements, one obtains the formulas in the following algorithm for predicting the pore humidity distributions at various times $t$.

$$
\text { 1. } \delta(t)=\frac{\gamma+1}{2} D \tanh \tau \frac{t-t_{0}}{\tau_{\mathrm{sh}}}, \quad h_{\mathrm{c}}(t)=h_{0}
$$

2. If $\delta(t) \leq D / 2$, go to 5

3. $\delta(t)=D / 2$

4. $h_{\mathrm{c}}(t)=h_{\mathrm{e}}+\left(1+\frac{1}{\gamma}\right)\left(h_{0}-h_{\mathrm{e}}\right) \tanh \sqrt{\frac{t-t_{0}}{\tau_{\mathrm{sh}}}}$

5. Evaluate $h(x, t)$ from (5).

\subsection{Improvements of long-term creep and shrinkage prediction based on short-time measurements}

Close prediction of the future creep and shrinkage is impossible without short-time measurements on the given concrete. Since this is a very important problem, a recently published model (Bažant and Baweja 1995) taking into account the coupling with water diffusion will now be described. 


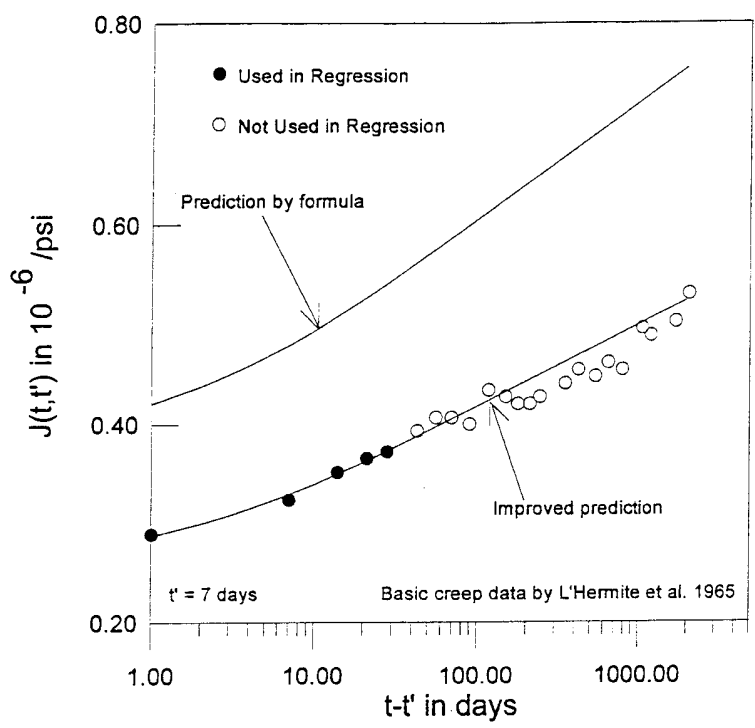

Fig. 2. Example of improving the creep prediction bythe use of short-time test data.

An important advantage of the B3 Model compliance function $J\left(t, t^{\prime}\right)$ (Equation 7, pp. 359, and 15 , pp. 363, in Bažant and Baweja 1995) is that all the free parameters for creep with elastic deformation, that is, $q_{1}, q_{2}, q_{3}, q_{4}, q_{5}$, are contained in the formulas linearly. Therefore, linear regression based on the least-square method can be used to identify these parameters from test data, so as to minimize the value of the coefficient of variation of the deviations of model prediction from the available data points, $\bar{\omega}_{\text {all }}^{2}$. The linearity also applies to parameter $\varepsilon_{\mathrm{sh} \infty}$ for shrinkage. Thus the only nonlinear parameter of the entire formulation is the shrinkage half-time $\tau_{\mathrm{sh}}$.

The largest source of uncertainty of creep and shrinkage prediction model is the dependence of model parameters on the composition and design strength of concrete. This uncertainty can be greatly reduced by carrying out short-time measurements on the given concrete and adjusting the values of the same model parameters accordingly. Carrying out measurements of at least short-time creep and shrinkage (of duration 1-3 months) is important especially for special concretes such as high strength concretes. Various types of admixtures, superplasticizers and pozzolanic ingredients used in these concretes have been found to have a significant effect on creep and shrinkage of concrete. Empirical formulas for the effects of all these ingredients on the model parameters would be very difficult to formulate because of the great variety of additives and different combinations used. Compared to other models, including the original BP Model, the solidification theory which is the basis of the present model has the advantage that the adjusted values of model parameters except $C_{0}$ can be easily obtained by linear regression of the short-time test data.

To illustrate the procedure, consider now the data for creep at drying by L'Hermite et al. (1965)and L'Hermite and Mamillan (1970), for which the present formulae for the effect of composition and strength do not give a good prediction, as is apparent from Fig. 2. We now pretend we know only the first 5 data points for the first 28 days of creep duration, which are shown by the solid circles. We consider the updated compliance function in the form:

$J\left(t, t^{\prime}\right)=p_{1}+p_{2} F\left(t, t^{\prime}\right)$

in which $p_{1}$ and $p_{2}$ have the role of updated parameters $q_{1}$ and $q_{2}$, and

$F\left(t, t^{\prime}\right)=C_{0}\left(t, t^{\prime}\right)+C_{\mathrm{d}}\left(t, t^{\prime}, t_{0}\right)$

This function is evaluated according to the model, using the formulae for the effect of composition parameters and strength. If the data agreed with the form of the present model B3 exactly, the plot of $J\left(t, t^{\prime}\right)$ versus $F\left(t, t^{\prime}\right)$ would have to be a single straight line for all $t, t^{\prime}$ and $t_{0}$. The vertical deviations of the data points from this straight line represent errors which are regarded as random and are to be minimized by least-square regression. So we consider the plot of the known (measured) short-time values $Y=J\left(t, t^{\prime}\right)$ (up to 28 days of creep duration) versus the corresponding values of $X=F\left(t, t^{\prime}\right)$, calculated from model B3, and pass through these points the regression line $Y=A X+$ $B$. Then the slope $A$ and the $Y$-intercept $B$ of this line give the values of $p_{1}$ and $p_{2}$ that are optimum in the sense of the least-square method; $A=p_{2}$ and $B=p_{1}$. According to the well-known normal equations of least-square linear regression,

$p_{2}=\left[n \Sigma\left(F_{i} J_{i}\right)-\left(\Sigma F_{i}\right)\left(\Sigma J_{i}\right)\right]\left[n \Sigma\left(F_{i}^{2}\right)-\left(\Sigma F_{i}\right)^{2}\right]^{-1}$

and $p_{1}=\bar{J}-p_{2} \bar{F}$ where subscripts $i=1,2, \ldots n$ 
label the known data points, $n$ is their total number, $F=F\left(t, t^{\prime}\right), J=J\left(t, t^{\prime}\right), \bar{J}$ is the mean value of all the measured $J$ and $\bar{F}$, is the mean value of all the corresponding $F$. Obviously, the improvement of long-time predictions achieved by shorttime measurements is in this example very significant. The well-known formulae of linear regression also yield the coefficients of variation of $p_{1}$ and $p_{2}$, which in turn provide the coefficient of variations of $J\left(t, t^{\prime}\right)$ for any given $t$ and $t^{\prime}$.

For planning of short-time creep measurements, note that prediction improvement based on short-time data is more successful if the creep measurements begin at very short times after loading (and likewise for shrinkage, if the measurements begin immediately after the stripping of the mold). The reason is that the creep curves are known to be smooth through the entire range from $0.0001 \mathrm{~s}$ to 30 years. In our example, the first reading was taken as late as 1 day after loading, as is often done, and therefore we needed up to 28 days of creep data for prediction improvement. In a similar example using a different formulation it was shown that if the first reading is taken as soon as possible after loading (within 1 min) and about six readings are taken in the first 2 days of load duration a similar improvement can be achieved using those readings only. Thus the duration of short time test could be reduced if readings are begun immediately after loading. Anyhow, for reliable prediction over five years of creep duration, short-time tests of at least 28 days duration (with the first reading immediately after loading and further readings equally spaced on the logarithmic scale for creep duration in hours) are recommended.

The shrinkage predictions, too, can be improved on the basis of the measurements of the given concrete. However, an important limitation has recently been noted (Bažant and Baweja, 1993; Bažant and Baweja 1995). The updating based only on short time measurements of shrinkage values is not possible unless the measurements extend into rather long times, at which the shrinkage curves begins to level off on approach to the final value. The reason is the special nonlinear form of the shrinkage formulae arising from the diffusion nature of the problem. If the time range of shrinkage measurements is not sufficiently long, the problem of fitting the shrinkage formula in Eqs. (9)-(12), pp. 360, of Bažant and Baweja (1995) to the measured strain values is an illposed problem. In other words, very different values of parameters $\varepsilon_{\mathrm{sh} \infty}$ and $\tau_{\mathrm{sh}}$ can give almost equally good fits of short-time data, as shown in Fig. 3 (taken from Bažant and Baweja, 1993). This is true not only for the present model B3 formulae (which in this case are the same in the BP and BP-KX models) but also for all other shrinkage formulae, including the Ross' hyperbola used in the ACI model (this formula does not give a good shape of the shrinkage curves and disagrees with the asymptotic forms for short and long times required by the RILEM Committee Guidelines). The problem is clear from Fig. 3 in which two shrinkage curves according to the
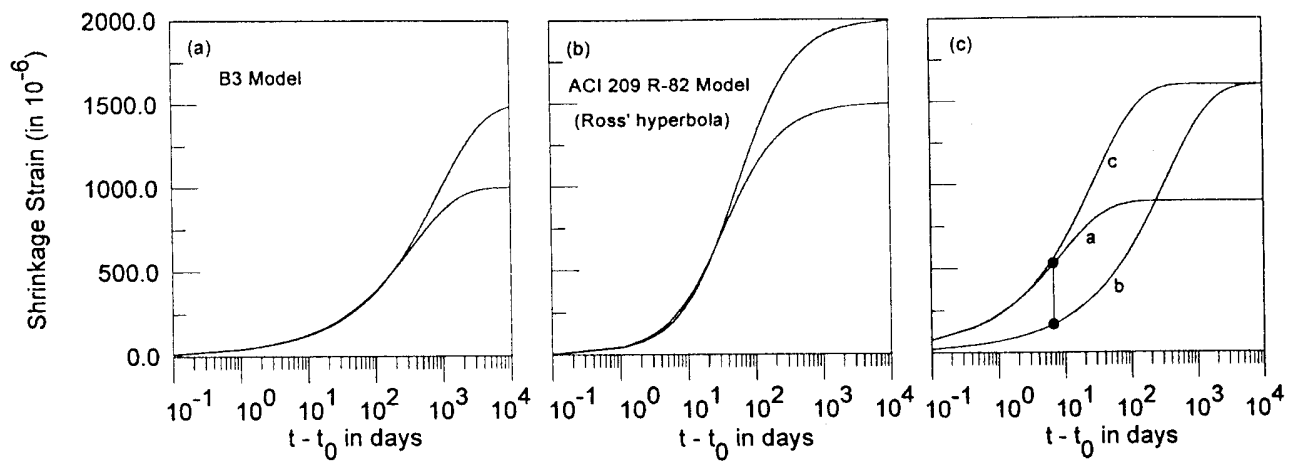

Fig. 3. Examples of shrinkage-time curves giving nearly the same initial shrinkage but very different final values; left: B3 Model and middle: ACI 209 Model. 


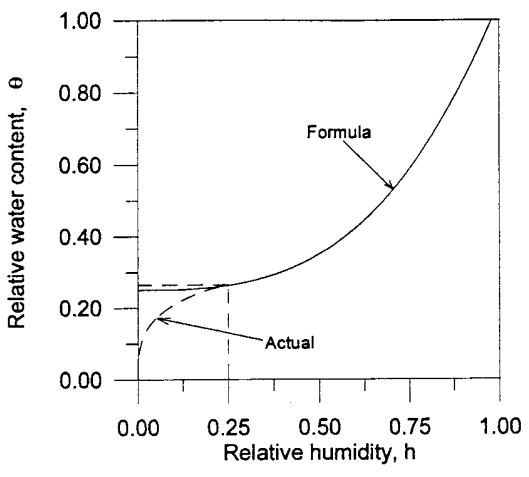

Fig. 4. Relative water content of concrete versus relative humididty $h$ in equilibrium.

present model or the ACI model, corresponding to very different parameter values, are shown to nearly coincide for a long period of time. If the data do not reach beyond the time at which the two curves shown in Fig. 3 begin to significantly diverge, there is no way to determine the model parameters unambiguously.

From such plots it must be concluded that a reliable determination of the final value of shrinkage would require, for 6 in. $(15 \mathrm{~cm})$ diameter cylinders, measurements of at least 5 years duration, which is unacceptable for a designer. Even with a 3 in. $(7.5 \mathrm{~cm})$ diameter cylinder, this would exceed 15 months. Increasing the temperature of the shrinkage tests to about $50^{\circ} \mathrm{C}$ would not shorten these times drastically and would raise further uncertainties due to the effect of temperature. A greater increase of temperature would change the shrinkage properties so much that inferences for the room temperature would become questionable. Significant acceleration of shrinkage would require reducing the thickness of the shrinkage specimen under about 1 in. (2.54 $\mathrm{cm})$, but in that case the specimens would have to be saw-cut from larger specimens and the threedimensional composite interaction between the mortar matrix and the aggregate pieces will very be different from bulk concrete.

Assume first that $\tau_{\mathrm{sh}}$ is known. The updated values of shrinkage prediction, labeled by primes, are considered as follows:

$\varepsilon_{\mathrm{sh}}^{\prime}=p_{6}\left[\varepsilon_{\mathrm{sh}}\left(t, t_{0}\right)\right]_{\tau_{\mathrm{sh}}}$ in which $\varepsilon_{\text {sh }}$ are the values predicted from the present model B3 based on the value of $\tau_{\mathrm{sh}}$, and $p_{6}$ is an update parameter. Consider that values $\varepsilon_{\mathrm{sh}_{i}}^{*}$ at times $t_{\mathrm{i}}$ have been measured. Let $\varepsilon_{\mathrm{sh}_{i}}$ be the values predicted for these times by the present model B3. The optimum update should minimize the sum of square deviations of the updated model from the data, that is:

$S=\sum_{i} \Delta_{i}^{2}=\sum_{i}\left(p_{6} \varepsilon_{\mathrm{sh}_{i}}-\varepsilon_{\mathrm{sh}_{i}}^{*}\right)^{2}=\operatorname{Min}$

A necessary condition of minimum is $\mathrm{d} S / \mathrm{d} p_{6}=0$. This yields the condition $\Sigma_{i}\left(p_{0} \varepsilon_{\mathrm{sh}_{i}}-\varepsilon_{\mathrm{sh}_{i}}^{*}\right) \varepsilon_{\mathrm{sh}_{i}}=0$. From this the value of the update parameter is calculated as:

$p_{6}=\frac{\sum_{i} \varepsilon_{\mathrm{sh}_{i}} \varepsilon_{\mathrm{sh}_{i}}^{*}}{\sum_{i} \varepsilon_{\mathrm{sh}_{i}}^{2}}$

Next consider the practical case, in which $\tau_{\mathrm{sh}}$ is not known in advance. To circumvent the aforementioned ill-posedness of the shrinkage updating problem, the following idea was recently proposed by Bažant and by Bažant and Baweja (1995). It has been known for a long time that shrinkage strains are approximately proportional to the water loss, denoted as $\Delta w$. The water loss can be easily measured simultaneously with shrinkage tests. Now, an important point to realize is that the final value $w_{\infty}(0)$ of water loss at complete drying (corresponding to zero relative humidity) is easily determined by heating the test specimen to $100^{\circ} \mathrm{C}$ after the conclusion of the short-time test. Using the approximately known shape of the desorption isotherm shown in Fig. 4, one may then estimate the final water loss $\Delta w_{\infty}(h)$ corresponding to drying at humidity $h$;

$\Delta w_{\infty}(h) \approx 0.75\left[1-\left(\frac{h}{0.98}\right)^{3}\right] \Delta w_{\infty}(0)$

This equation satisfies the condition that there is no water loss for $h \approx 0.98$ (in water immersion, $h=1$, there is water gain). For $h<0.24$, this equation is invalid, but such low humidities are usually not of interest.

Because Equations (9), (10) and (12) on p. 360 of Bažant and Baweja (1995) were derived from 
diffusion theory, assuming proportionality to water loss, the evolution of water loss with time should approximately follow the same equation as (10), p. 360 of Bažant and Baweja (1995), that is:

$\frac{\Delta w}{w_{\infty}}=\tanh \sqrt{\frac{t-t_{0}}{\tau_{\mathrm{sh}}}}$

This equation is easily rearranged to a linear form:

$t-t_{0}=\tau_{\mathrm{sh}} \psi, \quad$ with $\psi=\left[\tanh ^{-1}\left(\frac{\Delta w}{w_{\infty}}\right)\right]^{2}$

Now consider that at times $t_{\mathrm{i}}$ of shrinkage measurements the values of water loss $\Delta w_{i}$ and the corresponding values of $\psi_{i}$ have been determined. The optimum value of $\tau_{\mathrm{sh}}$ must minimize the sum of square deviations, i.e.

$S=\sum_{i}\left[\tau_{\mathrm{sh}} \psi-\left(t_{i}-t_{0}\right)\right]^{2}=\operatorname{Min}$

A necessary condition of minimum $\mathrm{d} S / \mathrm{d} \tau_{\mathrm{sh}}=0$. This yields the linear equation $\Sigma_{i}\left[\tau_{\mathrm{sh}} \psi_{i}-\left(t_{i}-\right.\right.$
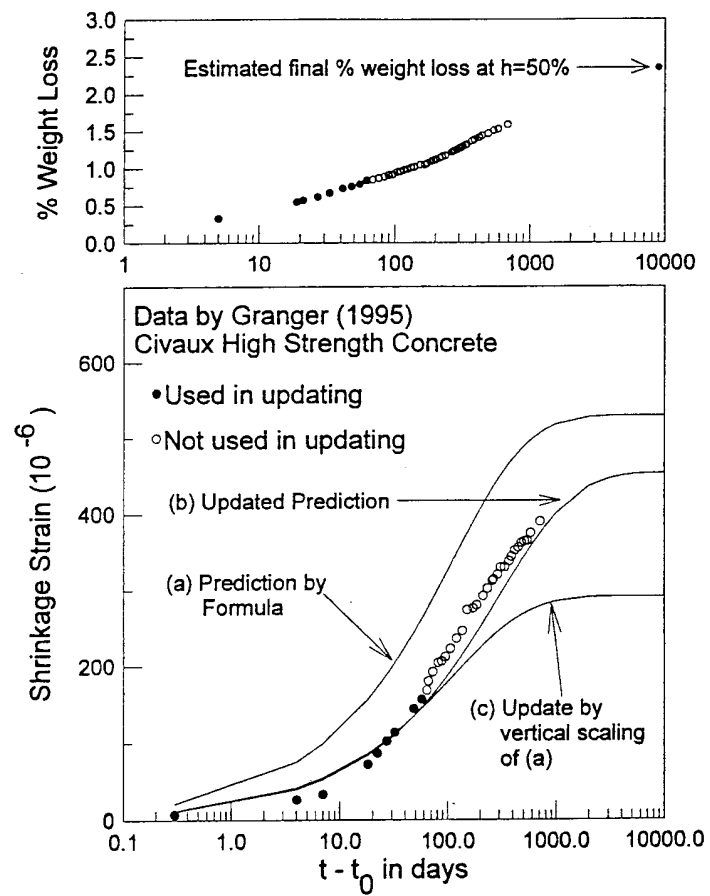

Fig. 5. Updating of long-term shrinkage prediction using short-term measurements at LCPC reported by Granger and Bažant, 1995. $\left.\left.t_{0}\right)\right] \psi_{i}=0$. From this, the desired updated value of $\tau_{\mathrm{sh}}$ is:

$\tau_{\mathrm{sh}}=\frac{\sum_{i}\left(t_{i}-t_{0}\right) \psi_{i}}{\sum_{i} \psi_{i}^{2}}$

Based on this value one may then use Eq. (7) to obtain the updating parameter $p_{6}$ for the shrinkage values as indicated before.

An example of the updating procedure, using shrinkage data of Granger measured at LCPC for the concrete of the Civaux nuclear power plant containment, is shown in Fig. 5.

It should be noted that although the relationship of water loss and shrinkage underlying the foregoing equations is reasonably well established and widely accepted, a direct check of this updating procedure has not yet been made. The proposed method deserves deeper accuracy evaluation.

\section{Acknowledgements}

Partial financial support from National Science Foundation under grant MSS-911476 to Northwestern University is gratefully acknowledged.

\section{References}

Aleksandrovskii, S.V., 1959. On thermal and hygrometric properties of concrete related to heat and moisture exchange (in Russian), Akad. Stroit. i Arkhitektury USSR (Moscow), Nauchno-Issled. Inst. Betona i Zhelezobetona (NIIZhB) Issled. Svoistv Betona, Zhelezob. Konstr., Trudy Inst., No. 4, pp. 184-214.

Alvaredo, A.M., Wittman, F.H., 1993. Shrinkage as influenced by strain softening and crack formation. in Creep and Shrinkage of Concrete, Proceedings of Fifth International RILEM Symposium, Barcelona, Spain, pp. 103-113.

Bažant, Z.P., 1993. Current status and advances in the theory of creep and interaction with fracture. In: Bažant, Z.P., Carol, I. (Eds.), Proceedings of the Fifth International RILEM Symposium on Creep and Shrinkage of Concrete (ConCreep 5). UPC, Barcelona, September, E\&FN Spon, London, pp. 291-307.

Bažant, Z.P., 1994. Creep and thermal effects in concrete structures: A conspectus of some new developments. Proceedings of Computational Modelling of Concrete Struc- 
tures (EURO-C). Innsbruck, Austria, March, Pineridge Press, pp. 461-480.

Bažant, Z.P., 1995. Creep and damage in concrete. In: Skalny, J., Mindess, S. (Eds.), Materials Science of Concrete IV. American Ceramic Society, Westerville, OH, pp. 355-389.

Baweja, S., Dvorak, G.J., Bažant, Z.P., 1998. Triaxial composite model for basic creep of concrete. J. Eng. Mech. ASCE 124 (9), 959-966.

Bažant, Z.P., Xi, Y., Baweja, S., 1993. Improved prediction model for time dependent deformations of concrete: part-7 Short form of BP-KX model, Statistics and extrapolation of short-time data. Mater. Struct. 26, 567-574.

Bažant, Z.P., Baweja, S., 1995. Justification and refinement of Model B3 for concrete creep and shrinkage. 1. Statistics and sensitivity. Mater. Struct. 28, 415-430.

Bažant, Z.P., Baweja, S., 1995. Creep and shrinkage prediction model for analysis and design of concrete structures model B3, in collaboration with RILEM Committee TC 107-GCS, (RILEM Recommendation). Mater. Struct. (RILEM, Paris) 28, 357-365; with Errata, Vol. 29 (March 1996), pp. 126.

Bažant, Z.P., Baweja, S., 1995b. Justification and refinement of Model B3 for concrete creep and shrinkage. Mater. Struct. 28, 415-430 RILEM, Paris.

Bažant, Z.P., Baweja, S., 1995, Creep and shrinkage prediction model for analysis and design of concrete structures model B3, in collaboration with RILEM Committee TC 107-GCS (RILEM Recommendation). Mater. Struct. (RILEM, Paris) 28, 357-365; with Errata, Vol. 29 (March 1996), pp. 126.

Bažant, Z.P., Baweja, S., 2000. Creep and shrinkage prediction model for analysis and design of concrete structures (Model B3). In: AlManasseer, A., (Ed.), Creep and Shrinkage of Concrete, ACI Special Publication, (extended and improved version of Bažant and Baweja, 1995a,b,c), in press.

Bažant, Z.P., Hauggaard, B., Baweja, S., Ulm, F.-J., 1997. Microprestress-solidification theory for aging and drying creep of concrete. J. Eng. Mech. ASCE 123, in press.

Bažant, Z.P., Kim, J.-K., 1991. Consequences of diffusion theory for shrinkage of concrete. Mater. Struct. 24 (143), 323-326 RILEM, Paris.

Bažant, Z.P., Kim, J.-K., 1991a. Consequences of diffusion theory for shrinkage of concrete. Mater. Struct. 24, 323326.

Bažant, Z.P., Kim, J.-K., 1991. Improved prediction model for time dependent deformations of concrete Part 1: Shrinkage, Mater. Struct. 24 (1991), pp. 327-345, Part 2: Basic Creep, Mater. Struct. 24 pp. 409-42, Part 3: Creep at drying, Mater. Struct. 25(1992), pp. 21-28, Part 4: Temperature effects, Mater. Struct. 25(1992), pp. 84-94.

Bažant, Z.P., Najjar, L.J., 1972. Nonlinear water diffusion in nonsaturated concrete. Mater. Struct. 5, 3-20 RILEM Paris.

Bažant, Z.P., Prasannan, S., 1989. Solidification theory for concrete creep: I. formulation, and II. verification and application. ASCE J. Eng. Mech. 115 (8), 1691-1725.
Bažant, Z.P., Raftshol, W.J., 1982. Effect of cracking in drying and shrinkage specimens. Cem. Concr. Res. 12, 209-226 Disc. 797-798.

Granger, L.P., Bažant, Z.P., 1995. Effect of composition on basic creep of concrete and cement paste. ASCE J. Eng. Mech. 121 (11), 1261-1270.

Hansen, T.C., Mattock, A.H., 1966. Influence of size and shape of member on the shrinkage and creep of concrete. ACI J. 63, 267-290.

L'Hermite, R.G., Mamillan, M., Lefèvre, C., 1965. Nouveaux résultats de recherches sur la déformation ét la rupture du béton. Ann. Inst. Techn. Bâtim. Trav. Publics 18 (207208), 323-360.

L'Hermite, R.G., Mamillan, M., 1970. Influence de la dimension des éprouvettes sur le retrait. Ann. Inst. Techn. Bâtim. Trav. Publics 23 (270), 5-6.

Neville, A.M., Dilger, W.H., Brooks, J.J., 1983. Creep of Plain and Structural Concrete. Construction Press, London and New York.

Parrott, L.J., 1991. Factors influencing relative humidity in concrete. Mag. Concr. Res. 43 (154), 45-52.

RILEM Committee TC-69, 1988. State of the art in mathematical modeling of creep and shrinkage of concrete. In: Bažant, Z.P., (Ed.), Mathematical Modeling of Creep and Shrinkage of Concrete, Wiley, Chichester and New York, pp. 57-215; and in prelim. form: State-of-art report on creep and shrinkage of concrete: mathematical modeling, Preprints, Fourth RILEM International Conference on Creep and Shrinkage of Concrete, 1986, pp. 41-80.

RILEM TC-69, 1988. Conclusions for structural analysis and for formulation of standard design recommendations, In: Bažant, Z.P., (Ed.), Mathematical Modeling of Creep and Shrinkage of Concrete (Chapter 6), Wiley, Chichester and New York, 20, pp. 395-398.

RILEM Techn. Com. TC-107, 1995. Guidelines for characterizing concrete creep and shrinkage in structural design codes or recommendations. Mater. Struct. 28, pp. 52-55.

RILEM Recommendation, 1998. Measurement of Time-Dependent Strains of Concrete, prepared by Subcomm. (4 of RILEM Committee TC107-CSP) In: Acker, P., Bažant, Z.P., Chern, J.-C., Huet, C., Wittmann, F.H., (Eds.), Mater. Struct. (RILEM, Paris) 31 (No. 212, October), pp. 507-512.

Troxell, G.E., Raphael, J.E., Davis, R.W., 1958. Long-time creep and shrinkage tests of plain and reinforced concrete. Proc. ASTM 58, 1101-1120.

\section{Further Reading}

Abrams, M.S., Gustaferro, A.H., 1968. Fire endurance of concrete slabs as influenced by thickness, aggregate type, and moisture. J. Portland Cem. Assoc. Res. Dev. Lab. 10 (2), 9-24 PCA Bulletin 223. 
Abrams, M.S., Monfore, G.E., 1965. Application of a small probe-type relative humidity gage to research on fire resistance of concrete. J. Portland Cem. Assoc. Res. Dev. Lab. 7 (3), 2-12 PCA Bulletin 186.

Abrams, M.S., Orals, D.L., 1965. Concrete drying methods and their effect on fire resistance. Moisture of materials in relation to fire tests. STP No. 385, American Society of Testing Materials (PCA Bulletin 181) pp. 57-32.

ACI Committee 209, 1982. Prediction of creep, shrinkage and temperature effects in concrete structures,(ACI 209-82), American Concrete Institute Detroit, pp. 108.

Bažant, Z.P., 1972. Prediction of concrete creep effects using age-adjusted effective modulus method. Am. Concr. Inst. J. $69,212-217$.

Bažant, Z.P., 1999. Criteria for rational prediction of creep and shrinkage of concrete, In: Ulm, F.-J., Prat, M., Calgaro, J.-A., Carol, I., (Eds.), Revue Française de Génie Civil 3 (3-4), 61-89; also in: Creep and Shrinkage of Concrete, Hermès Science Publications, Paris, pp. 61-89.

Bažant, Z.P., Carreira, D., Walser, A., 1975. Creep and shrinkage in reactor containment shells. J. Struct. Div. Am. Soc. Civil Eng. 101, 2117-2131.

Bažant, Z.P., Kim, J.-K., Panula, L., 1991. Improved prediction model for time-dependent deformations of concrete: part 1-shrinkage. Mater. Struct. 24 (143), 327-345 RILEM, Paris.

Bažant, Z.P., Baweja, S., 1996. Short form of creep and shrinkage prediction model B3 for structures of medium sensitivity (Addendum to RILEM Recommendation TC 107-GCS). Mater. Struct. (Paris) 29 (December), pp. 587593.

Bažant, Z.P., Chern, J.C., 1985. Concrete creep at variable humidity: constitutive law and mechanism. Mater. Struct. $18,1-20$.

Bažant, Z.P., Huet, C., 1999. Thermodynamic functions for ageing viscoelasticity: integral form without internal variables. Int. J. Solids Struct. 36, 3993-4016.

Bažant, Z.P., Kaplan, M.F., 1996. Concrete at High Temperatures: Material Properties and Mathematical Models (monograph and reference volume). Addison-Wesley, London, pp. 412-424.

Bažant, Z.P., Panula, L., 1978. Practical prediction of time dependent deformations of concrete. Parts I-VI Mater. Struct. 11 (1978) pp. 307-316, 317-328, 425-434, 12 (1979) pp. 169-183.

Bažant, Z.P., Panula, L., Kim, J.-K., Xi, Y., 1992. Improved prediction model for time dependent deformations of concrete: part 6-simplified code-type formulation. Mater. Struct. 25, 219-223.

Bažant, Z.P., Xi, Y., 1993. Stochastic drying and creep effects in concrete structures. J. Struct. Eng. ASCE 119 (1), 301322.

Bažant, Z.P., Xi, Y., 1994. Drying creep of concrete: constitutive model and new experiments separating its mechanisms. Mater. Struct. 27, 3-14.

Bažant, Z.P., Xi, Y., 1995. Continuous retardation spectrum for solidification theory of concrete creep. ASCE J. Eng. Mech. 121 (2), 281-288.
Brooks, J.J., 1989. Influence of mix proportions, plasticizers and superplasticizers on creep and drying shrinkage of concrete. Mag. Concr. Res. 41 (148), 145-153.

Brooks, J.J., 1992. Preliminary state of the art report: Elasticity, creep and shrinkage of concretes containing admixtures, slag, fly-ash and silica-fume ACI committee 209.

Browne, R.D., 1967. Properties of concrete in reactor vessels. In: Proceedings of Conference on Prestressed Concrete Pressure group C. Institution of Civil Engineers London, pp 11-31.

Carol, I., Bažant, Z.P., 1993. Viscoelasticity with aging caused by solidification of non-aging constituent. ASCE J. Eng. Mech. 119 (11), 2252-2269.

Carslaw, H.S., Jaeger, J.C., 1959. Conduction of Heat in Solids, Second edition. Oxford University Press, London, p. 97.

CEB-FIP Model Code, 1990. Design Code, Thomas Telford.

Gardner, N.J., Zhao, J.W., 1993. Creep and shrinkage revisited. ACI Mater. J. 90, 236-246.

Hancox, N.L., 1967. A note on the form of the rate of drying curve for cement paste and its use in analyzing the drying behavior of this material. RILEM Bull. 36, 197-201.

Hannant, D.J., 1967. Strain behaviour of concrete up to $95^{\circ} \mathrm{C}$ under compressive stresses. In: Proceedings of Conference on Prestressed Concrete Pressure group C, Institution of Civil Engineers London, pp. 57-71.

Hanson, J.A., 1968. Effects of curing and drying environments on splitting tensile strength. Am. Concr. Inst. J. 65, 535543.

Helmuth, R.A., Turk, D.H., 1967. The reversible and irreversible drying shrinkage of hardened portland cement and tricalcium silicate paste. J. Portland Cem. Assoc. Res. Dev. Lab. 9 (2), 8-21 PCA Bulletin 215.

Hughes, B.P., Lowe, I.R.G., Walker, J., 1966. The diffusion of water in concrete at temperatures between 50 and $95^{\circ} \mathrm{C}$. Br. J. Appl. Phys. 17, 252-263.

Keeton, J.R., 1965. Study of creep in concrete, Technical reports R333-I, R333-II, R333-III, US Naval civil engineering laboratory, Port Hueneme, California.

Kommendant, G.J., Polivka, M., Pirtz, D., 1976. Study of concrete properties for prestressed concrete reactor vessels, final report Report No. UCSESM 76-3 to General Atomic Company, Department of Civil Engineering, University of California, Berkeley.

RILEM Committee TC-69, 1988. Creep analysis of structures. In: Bažant, Z.P., (Ed.), Mathematical Modeling of Creep and Shrinkage of Concrete, Wiley, Chichester and New York, pp. 217-273.

Rostasy, F.S., Teichen, K.-Th., Engelke, H., 1972. Beitrag zur Klärung des Zussammenhanges von Kriechen und Relaxation bei Normal- beton, Amtliche Forschungsund Materialprüfungsanstalt für das Bauwesen, Heft 139 (Otto-Graf-Institute, Universität Stuttgart, Strassenbau und Strassenverkehrstechnik.

Takahashi, H., Kawaguchi, T., 1980. Study on Time-Dependent Behaviour of High Strength Concrete (Part 1)-Application of the Time-Dependent Linear Viscoelasticity 
Theory of Concrete Creep Behaviour, Ohbayashi-Gumi Research Institute Report, No.21, pp. 61-69.

Tsubaki, T., 1993. Sensitivity of factors in relation to prediction of creep and shrinkage of concrete in Creep and Shrinkage of Concrete. In: Proceedings of fifth international RILEM symposium, Barcelona, Spain, pp. 611-622.

Wallo, E.M., Yuan, R.L., Lott, J.L., Kesler, C.E., 1965. Sixth progress report on prediction of creep in structural concrete from short time tests. T\&AM report No. 658, Department of theoretical and applied mechanics, University of Illinois at Urbana.

Wittman, F.H., Bažant, Z.P., Alou, F., Kim, J.K., 1987. Statistics of shrinkage test data. Cem. Conc. Aggreg. 9 (2), $129-153$.

Xi, Y., Bažant, Z.P., Jennings, H.M., 1994a. Moisture diffusion in cementitious materials: absorption isotherms. Adv. Cem. Based Mater. 1, 248-257.

Xi, Y., Bažant, Z.P., Molina, L., Jennings, H.M., 1994b. Moisture diffusion in cementitious materials: moisture capacity and diffusivity. Adv. Cem. Based Mater. 1, 258-266. 